\title{
Cardiovascular Risk Factors in a French Canadian Population: Resolution of Genetic and Familial Environmental Effects on Blood Pressure Using Twins, Adoptees, and Extensive Information on Environmental Correlates
}

\author{
Treva Rice, George P. Vogler, Louis Pérusse, Claude Bouchard, \\ and D.C. Rao
}

Division of Biostatistics (T.R., G.P.V., D.C.R.) and Departments of Psychiatry and Genetics (D.C.R.), Washington University School of Medicine, St. Louis; Department of Human Genetics, University of Michigan Medical School, Ann Arbor, Michigan (L.P.); Physical Activity Sciences Laboratory, Laval University, Ste-Foy, Québec, Canada (L.P., C.B.)

\begin{abstract}
Genetic and environmental influences on systolic (SBP), diastolic (DBP), and mean arterial (MBP) blood pressure were examined using an expanded version of a path model in which parents and their singleton, twin, and adopted offspring were incorporated, and which also included an environmental index as an estimate of the underlying familial environmental component. Estimates of genetic heritability are lower in parents (10-15\%) than in offspring (40-50\%). Cultural heritability was significant for SBP (0.31) and MBP (0.40), and an intergenerational effect was found for DBP, with higher estimates in parents $(0.42)$ than in offspring (0.21). Marital resemblance was significant, and no support was found for differential maternal and paternal cultural transmission. Two novel results arising from this study are 1) gender-specific sibling effects, with greater female than male resemblance for SBP and MBP and the opposite pattern for DBP, and 2) the suggestion of extra twin resemblance arising on account of additional shared environments and resulting in greater like-sex than opposite-sex twin resemblance. The major conclusions drawn from this study are that 1) parameter estimates are stable with or without the use of extensive environmental indices, and 2) the addition of twins
\end{abstract}

Received for publication March 13, 1989; revision accepted May 18, 1989.

Address reprint requests to Dr. Treva Rice, Division of Biostatistics, Washington University School of Medicine, 660 S. Euclid, Box 8067, St. Louis, MO 63110.

(C) 1989 Alan R. Liss, Inc. 
and adoptees did not significantly impact the results, with the exception of a possible influence of the adoptees in estimates of cultural heritability for DBP. Combining both these features (i.e., extended relatives and environmental indices) enables testing for additional sources of familial aggregation, which is not possible using the traditional nuclear family approach and results in a more accurate assessment of the relative roles of heredity and environment on blood pressure than has been previously possible.

Key words: gender differences, heritability, nuclear families

\section{INTRODUCTION}

In a previous study of genetic and environmental influences on systolic, diastolic, and mean arterial blood pressure in French Canadian families [Pérusse et al, 1989], we found a higher proportion of variability explained by familial environment (from $30 \%$ to $42 \%$ ) than the approximately $11 \%$ reported by other family studies [see Williams et al., 1984; Burns and Lauer, 1986 for reviews] and the 20\% to 30\% reported in an adoption study [Annest et al., 1979]. The proportion of variance due to genetic factors in our study was higher in offspring (about 50\%) than in parents (about 10\%), with these estimates being generally higher than results previously reported using family data and lower than reports based on adult twin data [Feinleib and Garrison, 1979]. We attributed our findings to the use of extensive environmental indices, which were based on a nearly exhaustive set of putative environmental variables known to be related to the blood pressure phenotypes. The environmental index was necessary in order to disentangle the effects of genes and environments in nuclear families.

There are two limitations in all of the above studies. First, use of different family designs (e.g., twins versus family data) often resulted in conflicting estimates of the relative effects of heredity and environment on blood pressure. For example, twin studies generally provided higher estimates of genetic effects in comparison to results based on family or adoption designs. Second, a possible criticism of the path model used by Pérusse et al. [1989] is that the measured index of the environment may in some way bias the resulting parameter estimates. For example, inclusion in the index of variables that are genetically correlated with the phenotype will tend to underestimate genetic effects, with a compensatory increase in the estimate of familial environmental effects [Rao et al., 1984].

An alternate method of assessing the degree of genetic and environmental effects without resorting to indices is to use expanded family designs such as twins and adoptees. Under certain assumptions, twins provide more direct estimates of genetic effects, and adoptees allow direct assessment of environmental effects. Each approach involves some critical assumptions. The method using nuclear families with environmental index requires that the index consists of no genetic effects that are correlated with the phenotype. Twin studies are valid under the assumption that environmental effects shared by monozygotic twins are no greater than those shared by dizygotic twins, genetic effects are additive, and spouse resemblance is negligible or modeled adequately by including parents. Adoption studies require absence of selective placement and assume that adopting parents and adoptees are representative of the population in general. Any of these assumptions could conceivably be false, resulting in potential bias in parameter estimates. Yet, in most studies, only one modeling approach was used, in which case the critical assumptions are not readily verifiable. One step toward allaying criticisms of 
potential bias caused by failed assumptions is to combine the various approaches into a single model. This can be accomplished using a path model that incorporates various familial relationships (e.g., parent-offspring, twins, singleton siblings, and adopted siblings) and that is resolvable with or without use of environmental indices.

The major purpose of the present study is to expand the nuclear family path model [Rao et al., 1982] to incorporate twins and adoptees and to apply this model to blood pressure data from a French Canadian family study. The effects on the inference of using twins, adoptees, and environmental indices are pursued. The general design of the model allows us to address additional questions concerning blood pressure. For example, we evaluate whether sibling environmental effects are gender-specific and whether there is extra twin resemblance for blood pressure. Thus, the present study is expected to provide a more accurate assessment of the relative roles of heredity and environment on blood pressure than was previously possible.

\section{MATERIALS AND METHODS}

\section{The Family Study}

Families of French descent living within $80 \mathrm{~km}$ around Québec were recruited through the media during the years 1978 through 1981 to study the genetic effects on several physiological and biochemical traits. A total of 1,630 individuals, comprising 375 families, were ascertained. None were being treated for cardiovascular disease. Individuals in the parental generation $(\mathrm{N}=727)$ range in age from 30.2 to 59.5 years. Ages of the offspring generation, which includes adoptees, nonadopted singletons, and twins ( $\mathrm{N}=903$ ), range from 8.4 to 25.7 years. Determination of twin zygosity was established from a questionnaire and from several red blood cell antigens and enzymes, and also from the A, B, and C loci of the HLA system. Discordance in one of these loci was regarded as evidence for dizygosity. Using this number of genetic markers, the possibility of misclassification is below $1 \%$.

The total sample includes 1,630 individuals. Of the total sample, 69 were deleted from the analysis, as described below. For the parents, 11 were deleted because of their status as step-parent in the nuclear family, and one mother was deleted because of missing blood pressure data. In the offspring generation, 32 adoptees were deleted because age at adoption was greater than 1 year or because of a biological relationship with one or more members of the nuclear family. No twins were deleted from the analysis, although several unusual twin types should be pointed out. Three of the twin pairs were adopted ( $1 \mathrm{MZ}$ and $2 \mathrm{DZ}$ pairs); three families contained two twin pairs; and three families contained triplets. An additional 22 individuals in the offspring generation were deleted because of non-cohabitation with the nuclear family (e.g., moving out of the home or being a cousin or friend of the family). Finally, one entire family $(\mathrm{N}=4)$ was deleted because each parent was a sibling of the parents in another nuclear family group in the study. The final analysis sample of 1,560 individuals, comprising 374 families, includes $64 \mathrm{MZ}$ and $66 \mathrm{DZ}$ twin pairs and 145 adopted offspring.

All the physiological and behavioral measurements were obtained during a 1-day visit of the family to the laboratory. Questionnaires on physical activity and various lifestyle habits were administered individually to each member of the family by a trained interviewer. In addition, diaries pertaining to dietary intake and energy expenditure were completed by each family member during the 2 weeks preceding the visit to the 
laboratory. Individual interviews were then conducted with each subject to ensure completeness of the diaries. A more complete list of the variables is found in Pérusse et al. [1989].

\section{Measures}

The phenotypes used in the current study consist of systolic (SBP) and diastolic (DBP) blood pressures. Mean arterial blood pressure (MBP) was simply estimated as $\mathrm{DBP}+(\mathrm{SBP}-\mathrm{DBP}) / 3$. For a vast majority of the subjects, two readings were recorded for each of SBP and DBP, and the averages were used. Details of the protocol may be found in Pérusse et al. [1989]. A test-retest study was conducted in 61 subjects, and results revealed that the procedure was quite reproducible with intraclass reliability coefficients of 0.94 and 0.91 for SBP and DBP, respectively [Després et al., 1988].

\section{Data Adjustments}

The data adjustments are outlined in greater detail in Pérusse et al. [1989]. In summary, the effects of age were adjusted for by regressing a given blood pressure (BP) phenotype on a cubic polynomial in age in a stepwise manner, and retaining only the terms significant at the $5 \%$ level. The residual variance was also examined for age effects (heteroscedasticity) by regressing the residual on another cubic polynomial in age. After appropriate regression models were derived, each observation was then standarized by using the relevant fitted regression models. Thus, the effects of age on both the mean and variance of each BP phenotype were eliminated. The standardized $\mathrm{z}$ scores were then ranked and normalized. The normalized scores constitute the BP phenotypes used in the present study.

\section{Environmental Index}

Since familial environment is not directly measureable, a composite measure of all relevant environmental variables, called an "environmental index," may be used as an estimate of the familial environment [Rao et al., 1974, 1984]. A blood pressure (BP) index, generated for each individual and separately for each of the three BP phenotypes, is that linear function of the environmental variables which best predicts the BP phenotype. Construction of these indices is described in Pérusse et al. [1989]. Briefly, a total of 103 correlates of blood pressure encompassing such traits as diet, fitness, leisure activities and exercise, smoking, drinking, stress, obesity, and socioeconomic variables were considered as potentially relevant for indices. As a first screening step, a BP phenotype was regressed separately on each of these variables, and each was considered for further evaluation only if the regression was significant at the $20 \%$ level. A maximum of 24 variables for any one BP index were selected this way. A given BP phenotype was then regressed simultaneously on the previously selected variables in a stepwise manner, retaining only those terms that were significant at the 5\% level. A maximum of 15 variables for any one BP index were finally selected. The major variables which contributed to the indices across all three phenotypes were quetelet index, skinfolds, alcohol consumption, smoking, leisure activities, fitness measures, and dietary energy intake [see Pérusse et al., 1989, for specifics]. The predicted values from such multiple regressions were adjusted for age effects and then ranked and normalized as previously described for the BP phenotypes. The percent of blood pressure variance explained by the final BP index variables ranged from $16 \%$ to $21 \%$. 


\section{Path Analysis}

The path model used to analyze the BP phenotypes and indices, presented in Figure 1, is an extension of a contemporary path model [PATHMIX, Rao et al., 1982]. The extended model incorporates both types of twins, adopted offspring, and certain types of sex-specific environmental effects. It is assumed that a blood pressure phenotype $(P)$ results from the linear additive effects of an unmeasured genotype $(G)$, an unmeasured familial environment $(\mathrm{C})$, and an uncorrelated residual environment (not shown in the figure). The index (I) is assumed to be an estimate, albeit imperfect, of $\mathrm{C}$. The subscripts $\mathrm{M}$ and $\mathrm{F}$ in the parents refer to male and female, respectively. Twoletter subscripts were used for all offspring. The first letter denotes the type of offspring, where A refers to adopted offspring, D is a dizygotic twin, $M$ is a monozygotic

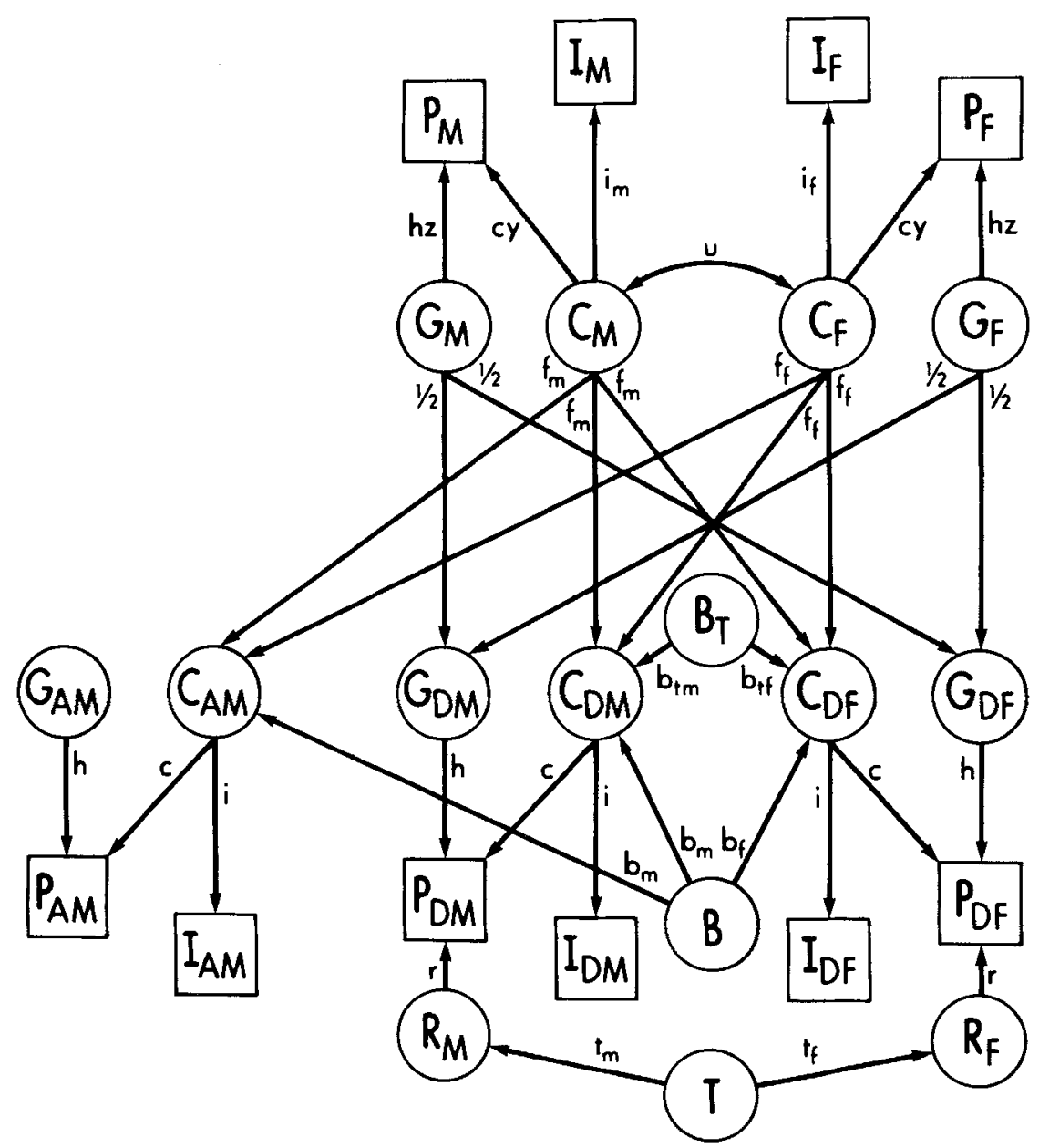

Fig. 1. Path diagram for the inheritance of blood pressure. The subscripts $M$ and $F$ stand for male and female parents, respectively, and AM, DM, and DF represent an adopted male, and opposite-sex dizygotic twin offspring. $G$ is genotype, $P$ is phenotype, $C$ is common environment with index $I, B$ and $B_{\Upsilon}$ are nontransmitted common sibship and twinship environments, and $T$ represents a source of additional twin resemblance acting through residual environments $\left(R_{M}\right.$ and $\left.R_{F}\right)$. 
twin, and $S$ represents a singleton offspring (the latter two types are not shown in the figure). The second letter refers to male (M) and female (F). Thus, in Figure 1, AM is an adopted male, and DM and DF are opposite-sex dizygotic twins. The latent variable $T$ represents a source of additional twin resemblance acting through residual environments $\left(R_{M}\right.$ and $\left.R_{F}\right)$, while $B_{T}$ and $B$ denote nontransmitted common twinship and common sibship environmental factors. Note that the effects of $\mathrm{B}$ apply to all offspring, whether singletons, twins, or adoptees. Thus, nontransmitted twin resemblance could arise through $\mathrm{T}, \mathrm{B}_{\mathrm{T}}$, and $\mathrm{B}$, while nontransmitted (singleton) sibling resemblance could only occur through $B$.

The 16 path model parameters corresponding to Figure 1 are defined in Table I. The effects of genotype and familial environment on a given phenotype incorporate intergenerational differences: whereas $h^{2}$ and $c^{2}$ are the genetic and cultural (familial environmental) heritabilities in offspring, they are $h^{2} z^{2}$ and $c^{2} y^{2}$ in parents. Specific maternal influences are incorporated by distinguishing the effects of paternal $\left(f_{\mathrm{m}}\right)$ and maternal $\left(f_{\mathrm{f}}\right)$ familial environments on that of an offspring, where the subscripts $m$ and $f$ refer to male and female parent, respectively. Marital resemblance is modeled in terms of a correlation $(u)$ between the familial environments of spouses. The effect of the common familial environment on the index (I) is denoted $i$ in the offspring, and $i_{\mathrm{m}}$ and $i_{\mathrm{f}}$ for male and female parent, respectively. Nontransmitted common sibship environmental effects are differentiated by gender of the offspring $\left(b_{\mathrm{m}}\right.$ and $\left.b_{\mathrm{f}}\right)$. Twinspecific effects are modeled in two ways: first, as a nontransmitted common twinship environmental effect, denoted by $b_{\mathrm{tm}}$ and $b_{\mathrm{tf}}$ for male and female twins, respectively (which is analogous to the nontransmitted common sibship environmental effect), and second, as an effect allowing correlations between twin residual environments $\left(t_{\mathrm{m}}\right.$ and $\left.t_{\mathrm{f}}\right)$.

The addition of twins and adoptees allows greater power for separating genetic and environmental effects under the assumptions discussed above. The twins allow a more direct assessment of the genetic effects $(h)$, while adopted siblings allow direct estimation of the environmental or cultural effects $(c)$. Thus, the index is not essential to disentangle primary genetic and environmental effects. The present data set does

\section{TABLE I. Definition of the Parameters of the Model}

\begin{tabular}{ll} 
Parameter \\
\hline$h$ & Effect of genotype on offspring's phenotype \\
$h z$ & Effect of genotype on parent's phenotype \\
$c$ & Effect of familial environment on offspring's phenotype \\
$c y$ & Effect of familial environment on parent's phenotype \\
$u$ & Correlation between parental familial environments \\
$i_{\mathrm{m}}$ & Effect of familial environment on male parent's index \\
$i_{\mathrm{f}}$ & Effect of familial environment on female parent's index \\
$i$ & Effect of familial environment on offspring's index \\
$f_{\mathrm{m}}$ & Effect of male parent's family environment on that of offspring he rears \\
$f_{\mathrm{f}}$ & Effect of female parent's family environment on that of offspring she rears \\
$b_{\mathrm{m}}$ & Effect of nontransmitted common sibship environment on male offspring's familial environment \\
$b_{\mathrm{f}}$ & Effect of nontransmitted common sibship environment on female offspring's familial environment \\
$b_{\mathrm{tm}}$ & Effect of nontransmitted common twinship environment on male twin's familial environment \\
$b_{\mathrm{tf}}$ & Effect of nontransmitted common twinship environment on female twin's familial environment \\
$t_{\mathrm{m}}$ & Effect of additional common twinship environment on male twin's residual environment \\
$t_{\mathrm{f}}$ & Effect of additional common twinship environment on female twin's residual environment \\
\hline
\end{tabular}


not include measures on the biological parents of the adoptees in order to test for selective placement. Although placement of the children was not based on blood pressure measurements, indirect selective placement could have occurred through a correlated variable such as socioeconomic status.

These arise 40 unique correlations among the phenotypes and indices in this model (defined in Table II). Following standard rules of path analysis [e.g., Li, 1975], expectations for these correlations have been derived (Table III). The statistical method of analysis fits the model directly to the family data under the assumption that the phenotypes and indices in a family jointly follow a multivariate normal distribution [see Rao et al., 1984]. The total log likelihood function for the entire sample of families is thus expressed as a function of the 40 correlations, 8 means (one for each of a phenotype and an index in father, mother, biological offspring, and adopted offspring), and 8 variances of the phenotypes and indices. Adopted and biological offspring means and variances are allowed to differ since any genotype-environment correlation would tend to reduce the adopted offspring estimates. Since the BP phenotypes and indices are normal scores, all 8 means should be close to zero and all 8 variances should be close to unity. Sample means and variances provide excellent estimates of the means and parental variances and are fixed at the sample values. Owing to variable sibship size, however, it is recommended that the variances of biological and adopted offspring's BP phenotypes and indices be estimated simultaneously by maximizing the log likelihood. By expressing the 40 correlations as functions of the 16 path coefficients, one can estimate either the correlations or the path coefficients, in addition to the four offspring variances, by maximizing the total log likelihood. Tests of hypotheses on the path coefficients are carried out using likelihood ratio tests.

\section{RESULTS}

\section{Correlational Analysis of Phenotypes Only}

Prior to fitting the path model to the data, several correlation models using only the BP phenotype data were examined in order to determine whether gender-specific effects that are not shown in Figure 1 should be explicitly modeled. For example, in the full path model the parentally transmitted cultural paths may be separated by gender of the offspring (e.g., decompose $f_{\mathrm{m}}$ into $f_{\mathrm{mm}}$ and $f_{\mathrm{mf}}$ for male parent to either male or female offspring, respectively).

Three correlation hypotheses were examined in order to determine the genderspecific effects that required modeling. In the first and most general hypothesis, both sibling correlations and parent-offspring correlations were allowed to vary by gender of the offspring in addition to that of the parents (i.e., distinguishing brother-brother from sister-sister, and father-son from father-daughter, etc.). In the second hypothesis, parent-offspring correlations were equated by gender of the offspring, while the sibling correlations remained different. The third and most restrictive hypothesis is analogous to the PATHMIX model, where correlations were not distinguished by gender of the offspring.

The parent-offspring correlations were all homogeneous by gender of the offspring $\left(\chi_{4}^{2}=1.16, P=.885\right.$ for SBP; $\chi_{4}^{2}=1.15, P=.886$ for DBP; and $\chi_{4}^{2}=1.15, P=$ .886 for MBP $)$. The sibling correlations were heterogeneous for $\operatorname{SBP}\left(\chi_{2}^{2}=9.41, P=\right.$ $.009)$, but were not significant for $\operatorname{DBP}\left(\chi_{2}^{2}=4.48, P=.089\right)$ and were of borderline 
TABLE II. Definition of the Correlations of the Model

\begin{tabular}{|c|c|}
\hline Paired variables ${ }^{\mathbf{a}}$ & Definition \\
\hline \multicolumn{2}{|l|}{ Phenotype-phenotype } \\
\hline $\mathrm{P}_{\mathrm{M}}, \mathrm{P}_{\mathrm{F}}$ & Correlation between father and mother \\
\hline $\begin{array}{l}P_{M}, P_{S M}=P_{M}, P_{D M} \\
\quad=P_{M}, P_{M M}=P_{M}, P_{S F} \\
\quad=P_{M}, P_{D F}=P_{M}, P_{M F}\end{array}$ & Correlation between father and offspring (either singleton or twin) \\
\hline $\begin{array}{l}\mathrm{P}_{\mathrm{F}}, \mathrm{P}_{\mathrm{SM}}=\mathrm{P}_{\mathrm{F}}, \mathbf{P}_{\mathrm{DM}} \\
\quad=\mathbf{P}_{\mathrm{F}}, \mathrm{P}_{\mathrm{MM}}=\mathrm{P}_{\mathrm{F}}, \mathrm{P}_{\mathrm{SF}} \\
\quad=\mathbf{P}_{\mathrm{F}}, \mathrm{P}_{\mathrm{DF}}=\mathbf{P}_{\mathrm{F}}, \mathbf{P}_{\mathrm{MF}}\end{array}$ & Correlation between mother and offspring (either singleton or twin) \\
\hline $\mathbf{P}_{\mathrm{M}}, \mathbf{P}_{\mathrm{AM}}=\mathrm{P}_{\mathrm{M}}, \mathrm{P}_{\mathrm{AF}}$ & Correlation between father and adopted offspring \\
\hline $\mathrm{P}_{\mathrm{F}}, \mathrm{P}_{\mathrm{AM}}=\mathbf{P}_{\mathrm{F}}, \mathrm{P}_{\mathrm{AF}}$ & Correlation between mother and adopted offspring \\
\hline $\mathrm{P}_{\mathrm{SM}}, \mathrm{P}_{\mathrm{SM}}$ & Correlation between singleton male siblings \\
\hline $\mathrm{P}_{\mathrm{SF}}, \mathrm{P}_{\mathrm{SF}}$ & Correlation between singleton female siblings \\
\hline $\mathrm{P}_{\mathrm{SM}}, \mathrm{P}_{\mathrm{SF}}$ & Correlation between singleton opposite-sex siblings \\
\hline $\mathrm{P}_{\mathrm{DM}}, \mathrm{P}_{\mathrm{DM}}$ & Correlation between male dizygotic twins \\
\hline $\mathrm{P}_{\mathrm{DF}}, \mathrm{P}_{\mathrm{DF}}$ & Correlation beteen female dizygotic twins \\
\hline $\mathrm{P}_{\mathrm{DM}}, \mathrm{P}_{\mathrm{DF}}$ & Correlation between opposite-sex dizygotic twins \\
\hline $\mathbf{P}_{\mathrm{MM}}, \mathrm{P}_{\mathrm{MM}}$ & Correlation between male monozygotic twins \\
\hline $\mathrm{P}_{\mathrm{MF}}, \mathrm{P}_{\mathrm{MF}}$ & Correlation between female monozygotic twins \\
\hline $\mathrm{P}_{\mathrm{SM}}, \mathrm{P}_{\mathrm{AM}}=\mathbf{P}_{\mathrm{AM}}, \mathrm{P}_{\mathrm{AM}}$ & Correlation between unrelated male siblings \\
\hline $\mathbf{P}_{\mathrm{SF}}, \mathbf{P}_{\mathrm{AF}}=\mathbf{P}_{\mathrm{AF}}, \mathbf{P}_{\mathrm{AF}}$ & Correlation between unrelated female siblings \\
\hline $\begin{array}{l}\mathrm{P}_{\mathrm{SM}}, \mathrm{P}_{\mathrm{AF}}=\mathrm{P}_{\mathrm{SF}}, \mathbf{P}_{\mathrm{AM}} \\
\quad=\mathbf{P}_{\mathrm{AM}}, \mathrm{P}_{\mathrm{AF}}\end{array}$ & Correlation between unrelated opposite-sex siblings \\
\hline \multicolumn{2}{|l|}{ Index-index } \\
\hline $\mathbf{I}_{\mathbf{M}}, \mathbf{I}_{\mathbf{F}}$ & Correlation between father and mother \\
\hline $\mathrm{I}_{\mathrm{M}}, \mathrm{I}_{\mathrm{O}}=\mathrm{I}_{\mathrm{M}}, \mathrm{I}_{\mathrm{T}}$ & Correlation between father and any offspring \\
\hline $\mathrm{I}_{\mathrm{F}}, \mathrm{I}_{\mathrm{O}}=\mathrm{I}_{\mathrm{F}}, \mathrm{I}_{\mathrm{T}}$ & Correlation between mother and any offspring \\
\hline $\mathrm{I}_{\mathrm{OM}}, \mathrm{I}_{\mathrm{OM}}$ & Correlation between any male non-twin siblings \\
\hline $\mathrm{I}_{\mathrm{OF}}, \mathrm{I}_{\mathrm{OF}}$ & Correlation between any female non-twin siblings \\
\hline $\mathrm{I}_{\mathrm{OM}}, \mathrm{I}_{\mathrm{OF}}$ & Correlation between any opposite-sex non-twin siblings \\
\hline $\mathrm{I}_{\mathrm{TM}}, \mathbf{I}_{\mathrm{TM}}$ & Correlation between any male twin siblings \\
\hline $\mathrm{I}_{\mathrm{TF}}, \mathrm{I}_{\mathrm{TF}}$ & Correlation between any female twin siblings \\
\hline $\mathbf{I}_{\mathrm{TM}}, \mathbf{I}_{\mathrm{TF}}$ & Correlation between any opposite-sex twin siblings \\
\hline \multicolumn{2}{|r|}{ 2018 } \\
\hline $\mathrm{P}_{\mathrm{M}}, \mathrm{I}_{\mathrm{F}}$ & Correlation between father's phenotype and mother's index \\
\hline $\mathrm{I}_{\mathrm{M}}, \mathrm{P}_{\mathrm{F}}$ & Correlation between father's index and mother's phenotype \\
\hline $\mathrm{P}_{\mathrm{M}}, \mathrm{I}_{\mathrm{O}}=\mathrm{P}_{\mathrm{M}}, \mathrm{I}_{\mathrm{T}}$ & Correlation between father's phenotype and any offspring's index \\
\hline $\mathrm{I}_{\mathrm{M}}, \mathrm{P}_{\mathrm{O}}=\mathrm{I}_{\mathrm{M}}, \mathrm{P}_{\mathrm{T}}$ & Correlation between father's index and any offspring's phenotype \\
\hline$P_{F}, I_{O}=P_{F}, I_{T}$ & Correlation between mother's phenotype and any offspring's index \\
\hline $\mathrm{I}_{\mathrm{F}}, \mathrm{P}_{\mathrm{O}}=\mathrm{I}_{\mathrm{F}}, \mathrm{P}_{\mathrm{T}}$ & Correlation between mother's index and any offspring's phenotype \\
\hline $\mathrm{P}_{\mathrm{OM}}, \mathrm{I}_{\mathrm{OM}}$ & Correlation between phenotype and index of any male non-twin siblings \\
\hline $\mathrm{P}_{\mathrm{OF}}, \mathrm{I}_{\mathrm{OF}}$ & Correlation between phenotype and index of any female non-twin siblings \\
\hline $\mathrm{P}_{\mathrm{OM}}, \mathrm{I}_{\mathrm{OF}}$ & $\begin{array}{l}\text { Correlation between phenotype and index of any } \\
\text { opposite-sex non-twin siblings }\end{array}$ \\
\hline $\mathrm{P}_{\mathrm{TM}}, \mathrm{I}_{\mathrm{TM}}$ & Correlation between phenotype and index of any male twin siblings \\
\hline $\mathrm{P}_{\mathrm{TF}}, \mathrm{I}_{\mathrm{TF}}$ & Correlation between phenotype and index of any female twin siblings \\
\hline $\mathrm{P}_{\mathrm{TM}}, \mathbf{I}_{\mathrm{TF}}$ & Correlation between phenotype and index of any opposite-sex twin siblings \\
\hline $\mathbf{P}_{M}, \mathrm{I}_{M}$ & Self phenotype-index correlation for fathers \\
\hline $\mathrm{P}_{\mathrm{F}}, \mathrm{I}_{\mathrm{F}}$ & Self phenotype-index correlation for mothers \\
\hline$P_{O}, I_{0}=P_{T}, I_{T}$ & Self phenotype-index correlation for any offspring \\
\hline
\end{tabular}

ap and I denote phenotype and index, respectively. Subscripts $M$ and $F$ refer to male and female, respectively; when prefaced with $\mathrm{S}, \mathrm{A}, \mathrm{D}, \mathrm{M}, \mathrm{O}$, or T, subscripts denote singleton, adopted, dizygotic, monozygotic, all nontwin, or all twin offspring, respectively, and when not prefaced with another subscript $M$ and $F$ refer to parents. 
TABLE III. Expected Correlations in the Path Model*

Paired variables ${ }^{\mathbf{a}}$

\begin{tabular}{|c|}
\hline 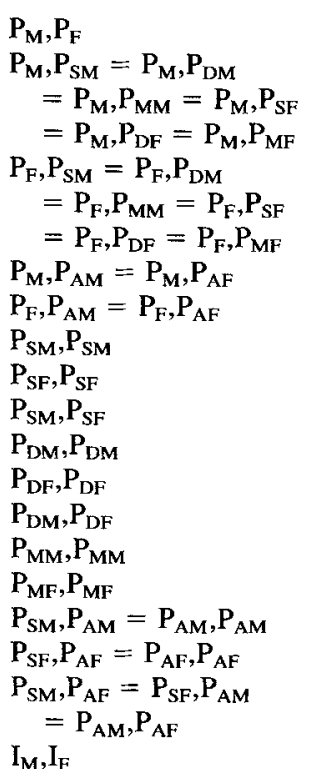 \\
\hline
\end{tabular}

$\mathrm{I}_{\mathrm{M}}, \mathrm{I}_{\mathrm{F}}$

$\mathrm{I}_{\mathrm{M}}, \mathrm{I}_{\mathrm{O}}=\mathrm{I}_{\mathrm{M}}, \mathrm{I}_{\mathrm{T}}$

$I_{F}, I_{O}=I_{F}, I_{T}$

$\mathrm{I}_{\mathrm{OM}}, \mathrm{I}_{\mathrm{OM}}$

$\mathrm{I}_{\mathrm{OF}}, \mathrm{I}_{\mathrm{OF}}$

$\mathbf{I}_{\mathrm{OM}}, \mathrm{I}_{\mathrm{OF}}$

$\mathbf{I}_{\mathrm{TM}}, \mathrm{I}_{\mathrm{TM}}$

$\mathbf{I}_{\mathrm{TF}}, \mathbf{I}_{\mathbf{T F}}$

$\mathbf{I}_{\mathrm{TM}}, \mathbf{I}_{\mathrm{TF}}$

$\mathbf{P}_{\mathrm{M}}, \mathrm{I}_{\mathrm{F}}$

$\mathrm{I}_{\mathrm{M}}, \mathrm{P}_{\mathrm{F}}$

$\mathbf{P}_{\mathrm{M}}, \mathrm{I}_{\mathrm{O}}=\mathbf{P}_{\mathrm{M}}, \mathrm{I}_{\mathrm{T}}$

$\mathbf{I}_{\mathrm{M}}, \mathbf{P}_{\mathrm{O}}=\mathrm{I}_{\mathrm{M}}, \mathrm{P}_{\mathrm{T}}$

$\mathbf{P}_{\mathrm{F}}, \mathrm{I}_{\mathrm{O}}=\mathbf{P}_{\mathrm{F}}, \mathrm{I}_{\mathrm{T}}$

$\mathrm{I}_{\mathrm{F}}, \mathrm{P}_{\mathrm{O}}=\mathrm{I}_{\mathrm{F}}, \mathbf{P}_{\mathrm{T}}$

$\mathrm{P}_{\mathrm{OM}}, \mathrm{I}_{\mathrm{OM}}$

$\mathrm{P}_{\mathrm{OF}}, \mathrm{I}_{\mathrm{OF}}$

$\mathrm{P}_{\mathrm{OM}}, \mathrm{I}_{\mathrm{OF}}$

$\mathrm{P}_{\mathrm{TM}}, \mathrm{I}_{\mathrm{TM}}$

$\mathrm{P}_{\mathrm{TF}}, \mathrm{I}_{\mathrm{TF}}$

$\mathrm{P}_{\mathrm{TM}}, \mathrm{I}_{\mathrm{TF}}$

$\mathrm{P}_{\mathrm{M}}, \mathrm{I}_{\mathrm{M}}$

$P_{\mathrm{F}}, \mathbf{I}_{\mathrm{F}}$

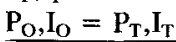

Expected correlation

$c^{2} y^{2} u$

$1 / 2 h^{2} z+\left(c^{2} y\right)\left(f_{\mathrm{m}}+f_{\mathrm{f}} u\right)$

$1 / 2 h^{2} z+\left(c^{2} y\right)\left(f_{\mathrm{f}}+f_{\mathrm{m}} u\right)$

$\left(c^{2} y\right)\left(f_{\mathrm{m}}+f_{\mathrm{f}} u\right)$

$\left(c^{2} y\right)\left(f_{\mathrm{f}}+f_{\mathrm{m}} u\right)$

$1 / 2 h^{2}+c^{2}\left(f_{\mathrm{m}}^{2}+f_{\mathrm{f}}^{2}+2 f_{\mathrm{m}} f_{\mathrm{f}} u+b_{\mathrm{m}}^{2}\right)$

$1 / 2 h^{2}+c^{2}\left(f_{\mathrm{m}}^{2}+f_{\mathrm{f}}^{2}+2 f_{\mathrm{m}} f_{\mathrm{f}} u+b_{\mathrm{f}}^{2}\right)$

$1 / 2 h^{2}+c^{2}\left(f_{\mathrm{m}}^{2}+f_{\mathrm{f}}^{2}+2 f_{\mathrm{m}} f_{\mathrm{f}} u+b_{\mathrm{m}} b_{\mathrm{f}}\right)$

$1 / 2 h^{2}+c^{2}\left(f_{\mathrm{m}}^{2}+f_{\mathrm{f}}^{2}+2 f_{\mathrm{m}} f_{\mathrm{f}} u+b_{\mathrm{m}}^{2}+b_{\mathrm{tm}}^{2}\right)+r^{2} t_{\mathrm{m}}^{2}$

$1 / 2 h^{2}+c^{2}\left(f_{\mathrm{m}}^{2}+f_{\mathrm{f}}^{2}+2 f_{\mathrm{m}} f_{\mathrm{f}} u+b_{\mathrm{f}}^{2}+b_{\mathrm{tf}}^{2}\right)+r^{2} t_{\mathrm{f}}^{2}$

$1 / 2 h^{2}+c^{2}\left(f_{\mathrm{m}}^{2}+f_{\mathrm{f}}^{2}+2 f_{\mathrm{m}} f_{\mathrm{f}} u+b_{\mathrm{m}} b_{\mathrm{f}}+b_{\mathrm{tm}} b_{\mathrm{tr}}\right)+r^{2} t_{\mathrm{m}} t_{\mathrm{f}}$

$h^{2}+c^{2}\left(f_{\mathrm{m}}^{2}+f_{\mathrm{f}}^{2}+2 f_{\mathrm{m}} f_{\mathrm{f}} \boldsymbol{u}+b_{\mathrm{m}}^{2}+b_{\mathrm{tm}}^{2}\right)+r^{2} t_{\mathrm{m}}^{2}$

$h^{2}+c^{2}\left(f_{\mathrm{m}}^{2}+f_{\mathrm{f}}^{2}+2 f_{\mathrm{m}} f_{\mathrm{f}} u+b_{\mathrm{f}}^{2}+b_{\mathrm{tf}}^{2}\right)+r^{2} t_{\mathrm{f}}^{2}$

$c^{2}\left(f_{\mathrm{m}}^{2}+f_{\mathrm{f}}^{2}+2 f_{\mathrm{m}} f_{\mathrm{f}} u+b_{\mathrm{m}}^{2}\right)$

$c^{2}\left(f_{\mathrm{m}}^{2}+f_{\mathrm{f}}^{2}+2 f_{\mathrm{m}} f_{\mathrm{f}} u+b_{\mathrm{f}}^{2}\right)$

$c^{2}\left(f_{\mathrm{m}}^{2}+f_{\mathrm{f}}^{2}+2 f_{\mathrm{m}} f_{\mathrm{f}} u+b_{\mathrm{m}} b_{\mathrm{f}}\right)$

$i_{\mathrm{m}} i_{\mathrm{f}} u$

$\left(i_{\mathrm{m}} i\right)\left(f_{\mathrm{m}}+f_{\mathrm{f}} u\right)$

$\left(i_{\mathrm{f}} i\right)\left(f_{\mathrm{f}}+f_{\mathrm{m}} u\right)$

$i^{2}\left(f_{\mathrm{m}}^{2}+f_{\mathrm{f}}^{2}+2 f_{\mathrm{m}} f_{\mathrm{f}} u+b_{\mathrm{m}}^{2}\right)$

$i^{2}\left(f_{\mathrm{m}}^{2}+f_{\mathrm{f}}^{2}+2 f_{\mathrm{m}} f_{\mathrm{f}} u+b_{\mathrm{f}}^{2}\right)$

$i^{2}\left(f_{\mathrm{m}}^{2}+f_{\mathrm{f}}^{2}+2 f_{\mathrm{m}} f_{\mathrm{f}} u+b_{\mathrm{m}} b_{\mathrm{f}}\right)$

$i^{2}\left(f_{\mathrm{m}}^{2}+f_{\mathrm{f}}^{2}+2 f_{\mathrm{m}} f_{\mathrm{f}} u+b_{\mathrm{m}}^{2}+b_{\mathrm{tm}}^{2}\right)$

$i^{2}\left(f_{\mathrm{m}}^{2}+f_{\mathrm{f}}^{2}+2 f_{\mathrm{m}} f_{\mathrm{f}} u+b_{\mathrm{f}}^{2}+b_{\mathrm{tf}}^{2}\right)$

$i^{2}\left(f_{\mathrm{m}}^{2}+f_{\mathrm{f}}^{2}+2 f_{\mathrm{m}} f_{\mathrm{f}} u+b_{\mathrm{m}} b_{\mathrm{f}}+b_{\mathrm{tm}} b_{\mathrm{tf}}\right)$

cy $u i_{\mathrm{f}}$

cy $u i_{\mathrm{m}}$

(cyi) $\left(f_{\mathrm{m}}+f_{\mathrm{f}} u\right)$

$\left(i_{\mathrm{m}} c\right)\left(f_{\mathrm{m}}+f_{\mathrm{f}} u\right)$

(cyi) $\left(f_{\mathrm{f}}+f_{\mathrm{m}} u\right)$

$\left(i_{\mathrm{f}} c\right)\left(f_{\mathrm{f}}+f_{\mathrm{m}} u\right)$

(ci) $\left(f_{\mathrm{m}}^{2}+f_{\mathrm{f}}^{2}+2 f_{\mathrm{m}} f_{\mathrm{f}} u+b_{\mathrm{m}}^{2}\right)$

(ci) $\left(f_{\mathrm{m}}^{2}+f_{\mathrm{f}}^{2}+2 f_{\mathrm{m}} f_{\mathrm{f}} u+b_{\mathrm{f}}^{2}\right)$

(ci) $\left(f_{\mathrm{m}}^{2}+f_{\mathrm{f}}^{2}+2 f_{\mathrm{m}} f_{\mathrm{f}} u+b_{\mathrm{m}} b_{\mathrm{f}}\right)$

(ci) $\left(f_{\mathrm{m}}^{2}+f_{\mathrm{f}}^{2}+2 f_{\mathrm{m}} f_{\mathrm{f}} u+b_{\mathrm{m}}^{2}+b_{\mathrm{mm}}^{2}\right)$

(ci) $\left(f_{\mathrm{m}}^{2}+f_{\mathrm{f}}^{2}+2 f_{\mathrm{m}} f_{\mathrm{f}} u+b_{\mathrm{f}}^{2}+b_{\mathrm{t} f}^{2}\right)$

(ci) $\left(f_{\mathrm{m}}^{2}+f_{\mathrm{f}}^{2}+2 f_{\mathrm{m}} f_{\mathrm{f}} u+b_{\mathrm{m}} b_{\mathrm{f}}+b_{\mathrm{tm}} b_{\mathrm{tf}}\right)$

cy $i_{\mathrm{m}}$

cy $i_{\mathrm{f}}$

$c i$

*Note: $r^{2}=1-h^{2}-c^{2}$.

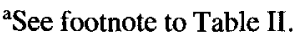


significance for $\operatorname{MBP}\left(\chi_{2}^{2}=5.90, P=.052\right)$. Other models involving gender-specific effects in the adoptee and twin groups were also explored; however, the number of pairs in these subgroups was too small for meaningful analyses. Table IV presents estimates of correlations under the most parsimonious model.

Similar correlational analyses were carried out using both BP phenotypes and indices, and the results were consistent with those above. However, the correlation between phenotype and index in fathers was found to be different from that in mothers, although there was no difference in gender-specific phenotype-index correlations in the offspring. Based on these correlational analyses, gender-specific parameters for siblings $\left(b_{\mathrm{m}}, b_{\mathrm{f}}\right.$, etc.) and for parental phenotype-index self correlations $\left(i_{\mathrm{m}}\right.$ and $\left.i_{\mathrm{f}}\right)$ were deemed necessary in the model-fitting analyses.

\section{Path Model Analysis of Phenotypes Only}

In order to understand the effect of indices on blood pressure, path analyses were carried out in two steps. In the first, only blood pressure phenotype data were used, while in the second both phenotypes and indices were used. For the phenotype-only data, not all of the parameters in the model are identified. Therefore, several simplifying assumptions were made as follows. For twins, the effects of $\mathrm{B}_{\mathrm{T}}$ on the familial environments $\left(\mathrm{C}_{\mathrm{DM}}, \mathrm{C}_{\mathrm{DF}}\right.$, say) are constrained so as to make them perfectly correlated, and twin residual correlations were dropped $\left(t_{\mathrm{m}}=t_{\mathrm{f}}=0\right)$. Thus, twin expectations reduce to be simply $\left(h^{2}+c^{2}\right)$ for MZs and $\left(1 / 2 h^{2}+c^{2}\right)$ for DZs. Additionally, $y$ and $z$ were fixed at 1.0 as they are not estimable in this data set.

Table V gives a summary of the alternate hypotheses tested for SBP, DBP, and MBP. For SBP, the hypotheses of no marital resemblance $(u=0)$, equal male and female common sibship environment $\left(b_{\mathrm{m}}=b_{\mathrm{f}}\right)$, no common sibship environment $\left(b_{\mathrm{m}}=b_{\mathrm{f}}=0\right)$, and no cultural heritability $(c=0)$ were all rejected. Nonsignificant $\chi^{2} \mathrm{~s}$ were associated with the hypotheses of $f_{\mathrm{m}}=f_{\mathrm{f}}$, and $h=0$. Thus, the most parsimonious model for SBP appears to be one where maternal and paternal environmental transmission to offspring is equated and there is no genetic heritability (i.e., $f_{\mathrm{m}}=f_{\mathrm{f}}$ and $h=0 ; \chi_{2}^{2}=2.78, P=.249$ ). However, one may argue against dropping $h$ from

TABLE IV. Maximum Likelihood Estimates of Familial Correlations*

\begin{tabular}{lcccc}
\hline Parameter & SBP & DBP & MBP & $N^{\mathrm{a}}$ \\
\hline Spouse & 0.209 & 0.285 & 0.263 & 343 \\
Father-child & 0.213 & 0.307 & 0.285 & 599 \\
Mother-child & 0.254 & 0.286 & 0.282 & 616 \\
Father-adopted child & 0.155 & 0.103 & 0.132 & 130 \\
Mother-adopted child & 0.170 & 0.101 & 0.149 & 125 \\
Brother-brother & 0.245 & 0.577 & 0.560 & 102 \\
Sister-sister & 0.553 & 0.577 & 0.560 & 77 \\
Brother-sister & 0.379 & 0.577 & 0.560 & 206 \\
DZ twins & 0.593 & 0.593 & 0.635 & 66 \\
MZ twins & 0.708 & 0.682 & 0.735 & 64 \\
Adopted siblings & 0.397 & 0.186 & 0.319 & 83 \\
\hline
\end{tabular}

*Note: Gender-specific sibling correlations are reported only if they were found to be significantly different (only for SBP).

${ }^{a}$ No. of pairs $(\mathrm{N})$ reflects the smaller of the estimated $\mathrm{N}$ [see Rao et al., 1982], and the maximum No. of pairs possible. 
TABLE V. Path Analysis of Phenotypes Only: Tests of Hypotheses for Systolic (SBP), Diastolic (DBP), and Mean Arterial (MBP) Blood Pressure

\begin{tabular}{|c|c|c|c|c|c|c|c|}
\hline \multirow[b]{2}{*}{ Hypothesis } & \multirow[b]{2}{*}{$d . f}$. & \multicolumn{2}{|c|}{ SBP } & \multicolumn{2}{|c|}{ DBP } & \multicolumn{2}{|c|}{ MBP } \\
\hline & & $x^{2}$ & $P$ & $x^{2}$ & $P$ & $x^{2}$ & $P$ \\
\hline$u=0$ & 1 & 15.31 & $<.001$ & 29.79 & $<.001$ & 24.24 & $<.001$ \\
\hline$f_{\mathrm{m}}=f_{\mathrm{f}}$ & 1 & 0.40 & .527 & 0.15 & .690 & 0.02 & .887 \\
\hline$b_{\mathrm{m}}=b_{\mathrm{f}}$ & 1 & 4.17 & .041 & 0.05 & .823 & 1.67 & .196 \\
\hline$b_{\mathrm{m}}=b_{\mathrm{f}}=0$ & 2 & 32.96 & $<.001$ & 51.08 & $<.001$ & 53.43 & $<.001$ \\
\hline$h=0$ & 1 & 2.29 & .130 & 10.95 & $<.001$ & 8.01 & .005 \\
\hline$c=0^{\mathrm{a}}$ & 6 & 77.20 & $<.001$ & 489.57 & $<.001$ & 104.98 & $<.001$ \\
\hline Parsimonious model $^{\mathrm{b}}$ & $1-2$ & 0.40 & .527 & 0.19 & .909 & 1.67 & .434 \\
\hline
\end{tabular}

${ }^{\mathrm{a}}$ When $c=0$, the parameters $u, f_{\mathrm{m}}, f_{\mathrm{f}}, b_{\mathrm{m}}$, and $b_{\mathrm{f}}$ are not identified, thus $6 d . f$.

'Parsimonious model for SBP by $\log$-likelihood ratio criterion is $f_{\mathrm{m}}=f_{\mathrm{f}}$ and $h=0\left(\chi_{2}^{2}=2.78, P=.249\right)$. However, Akaike's [1974] Information Criterion (AIC) supports the hypothesis of $f_{\mathrm{m}}=f_{\mathrm{f}}$ as the "best" model. Thus, the most parsimonious hypothesis chosen for SBP was $f_{\mathrm{m}}=f_{\mathrm{f}}$, with $1 d . f$. The parsimonious model for both DBP and MBP is $f_{\mathrm{m}}=f_{\mathrm{f}}$, and $b_{\mathrm{m}}=b_{\mathrm{f}}$, with $2 d . f$.

the model from two perspectives. First, as judged by the Akaike's [1974] Information Criterion (AIC-computed as twice the number of estimated parameters minus twice the log likelihood value, and the "best" model has the lowest AIC value), the hypothesis of $f_{\mathrm{m}}=f_{\mathrm{f}}$ (AIC $=12.40$ ) provides a marginally better fit than the hypothesis of $f_{\mathrm{m}}=f_{\mathrm{f}}$ and $h=0$ (AIC $\left.=12.78\right)$. Second, the standard error of $h$ in the general model (Table VI) suggests that the parameter may not be zero. Thus, the most parsimonious model chosen for SBP is simply $f_{\mathrm{m}}=f_{\mathrm{f}}$. For both DBP and MBP the parsimonious hypothesis is for equal maternal and paternal environmental transmission and equal common sibship environment effects (i.e., $f_{\mathrm{m}}=f_{\mathrm{f}}$ and $b_{\mathrm{m}}=b_{\mathrm{f}}$ ).

Parameter estimates for SBP, DBP, and MBP are given in Table VI under the general and the most parsimonious hypotheses. Under the most parsimonious hypothesis, estimates of the genetic heritabilities $\left(h^{2}\right)$ are $0.16,0.34$, and 0.28 for SBP, DBP, and MBP, respectively, and the cultural heritabilities $\left(c^{2}\right)$ are $0.53,0.37$, and 0.46 ,

TABIE VI. Path Analysis of Phenotypes Only: Parameter Estimates ( \pm Standard Error) Under the General and Parsimonious Hypotheses for Systolic (SBP), Diastolic (DBP), and Mean Arterial (MBP) Blood Pressure

\begin{tabular}{|c|c|c|c|c|c|c|}
\hline & \multicolumn{2}{|c|}{ SBP } & \multicolumn{2}{|c|}{ DBP } & \multicolumn{2}{|c|}{ MBP } \\
\hline & General & Parsimony ${ }^{\mathrm{a}}$ & General & Parsimony ${ }^{b}$ & General & Parsimony $^{\mathbf{b}}$ \\
\hline \multicolumn{7}{|c|}{ Estimated parameters } \\
\hline$h$ & $0.39 \pm 0.13$ & $0.40 \pm 0.13$ & $0.57 \pm 0.09$ & $0.58 \pm 0.09$ & $0.52 \pm 0.09$ & $0.53 \pm 0.09$ \\
\hline$c$ & $0.73 \pm 0.06$ & $0.73 \pm 0.06$ & $0.62 \pm 0.08$ & $0.61 \pm 0.08$ & $0.69 \pm 0.06$ & $0.68 \pm 0.07$ \\
\hline$u$ & $0.39 \pm 0.11$ & $0.39 \pm 0.11$ & $0.74 \pm 0.24$ & $0.77 \pm 0.24$ & $0.55 \pm 0.14$ & $0.57 \pm 0.15$ \\
\hline$f_{\mathrm{m}}$ & $0.16 \pm 0.10$ & $0.21 \pm 0.05$ & $0.30 \pm 0.60$ & $0.19 \pm 0.07$ & $0.21 \pm 0.13$ & $0.20 \pm 0.06$ \\
\hline$f_{\mathrm{f}}$ & $0.26 \pm 0.09$ & $0.21 \pm 0.05$ & $0.09 \pm 0.61$ & $0.19 \pm 0.07$ & $0.20 \pm 0.13$ & $0.20 \pm 0.06$ \\
\hline$b_{\mathrm{m}}$ & $0.55 \pm 0.10$ & $0.55 \pm 0.10$ & $0.90 \pm 0.14$ & $0.93 \pm 0.11$ & $0.77 \pm 0.10$ & $0.87 \pm 0.08$ \\
\hline$b_{\mathrm{f}}$ & $0.85 \pm 0.09$ & $0.86 \pm 0.09$ & $0.93 \pm 0.14$ & $0.93 \pm 0.11$ & $0.94 \pm 0.10$ & $0.87 \pm 0.08$ \\
\hline \multicolumn{7}{|c|}{ Derived parameters } \\
\hline$b_{\mathrm{tm}}$ & 0.75 & 0.76 & 0.22 & 0.03 & 0.53 & 0.36 \\
\hline$b_{\mathrm{tf}}$ & 0.38 & 0.38 & 0.00 & 0,03 & 0.01 & 0.36 \\
\hline
\end{tabular}

${ }^{\text {a}}$ Parsimonious model for $\mathrm{SBP}$ is $f_{\mathrm{m}}=f_{\mathrm{f}}$.

${ }^{\mathrm{b}}$ Parsimonious model for DBP and MBP is $f_{\mathrm{m}}=f_{\mathrm{f}}$ and $b_{\mathrm{m}}=b_{\mathrm{f}}$. 
respectively. Correlations between marital environments $(u)$ are very high, and parental environmental transmission $\left(f_{\mathrm{m}}=f_{\mathrm{f}}\right)$ is moderate and significant. The nontransmitted common sibship environmental effect for SBP is higher for females than for males, but no gender effect was found for either DBP or MBP.

\section{Path Analysis of Phenotypes and Indices}

Hypothesis tests for fitting both BP phenotype and indices are summarized in Table VII. For SBP, cultural heritability is the same in parents and children $(y=1)$, maternal and paternal cultural transmission could be equated $\left(f_{\mathrm{m}}=f_{\mathrm{f}}\right)$, and extra twin resemblance owing to correlated residuals is not implicated $\left(t_{\mathrm{m}}=t_{\mathrm{f}}=0\right)$. The hypotheses of no intergenerational differences in genetic effects $(z=1)$, no marital resemblance $(u=0)$, no genetic heritability $(h=0)$, no cultural heritability $(c=0)$, and no gender differences in common sibship $\left(b_{\mathrm{m}}=b_{\mathrm{f}}\right)$ and common twinship $\left(b_{\mathrm{tm}}=b_{\mathrm{tf}}\right)$ environmental effects were rejected. Finally, an hypothesis in which no sex differences were allowed as in the PATHMIX model (i.e., $i_{\mathrm{m}}=i_{\mathrm{f}}, b_{\mathrm{m}}=b_{\mathrm{f}}, b_{\mathrm{tm}}=b_{\mathrm{tf}}$, and $t_{\mathrm{m}}=t_{\mathrm{f}}$ ) was rejected. The most parsimonious hypothesis for SBP postulates no intergenerational differences in cultural heritability, equal maternal and paternal cultural transmission, and no extra twin resemblance through correlated residuals $\left(y=1, f_{\mathrm{m}}=f_{\mathrm{f}}\right.$, and $t_{\mathrm{m}}$ $=t_{\mathrm{f}}=0$ ). Examination of Table VII leads to the same parsimonious hypothesis for both DBP and MBP, except that for DBP cultural heritability is different in parents and children $(y \neq 1)$.

Table VIII gives the parameter estimates and standard errors under the general and most parsimonious hypotheses for all three BP phenotypes. Under the parsimonious hypothesis, estimates of genetic heritability in parents $\left(h^{2} z^{2}\right)$ are 0.15 for SBP and 0.11 for both DBP and MBP but are much higher in the offspring $\left(h^{2}=0.45,0.52\right.$, and 0.40 for SBP, DBP, and MBP, respectively). Cultural heritability $\left(c^{2}\right)$ was the same in both generations for SBP $(0.31)$ and MBP $(0.40)$ but was higher in parents

TABLE VII. Path Analysis of Phenotypes and Indices: Tests of Hypotheses for Systolic (SBP), Diastolic (DBP), and Mean Arterial (MBP) Blood Pressure

\begin{tabular}{|c|c|c|c|c|c|c|c|}
\hline \multirow[b]{2}{*}{ Hypothesis } & \multirow[b]{2}{*}{ d.f. } & \multicolumn{2}{|c|}{ SBP } & \multicolumn{2}{|c|}{ DBP } & \multicolumn{2}{|c|}{ MBP } \\
\hline & & $x^{2}$ & $P$ & $x^{2}$ & $P$ & $x^{2}$ & $P$ \\
\hline$y=z=1$ & 2 & 5.06 & .080 & 19.22 & $<.001$ & 11.15 & .004 \\
\hline$y=1$ & 1 & 0.26 & .610 & 7.53 & .006 & 0.28 & .597 \\
\hline$z=1$ & 1 & 4.04 & .044 & 16.70 & $<.001$ & 10.92 & $<.001$ \\
\hline$u=0$ & 1 & 32.24 & $<.001$ & 38.50 & $<.001$ & 39.78 & $<.001$ \\
\hline$f_{\mathrm{m}}=f_{\mathrm{f}}$ & 1 & 0.29 & .590 & 1.45 & .229 & 0.25 & .617 \\
\hline$b_{\mathrm{m}}=b_{\mathrm{f}}$ & 1 & 11.11 & $<.001$ & 5.07 & .024 & 7.41 & .007 \\
\hline$b_{\mathrm{m}}=b_{\mathrm{f}}=0$ & 2 & 30.24 & $<.001$ & 35.55 & $<.001$ & 37.58 & $<.001$ \\
\hline$b_{\mathrm{tm}}=b_{\mathrm{tf}}$ & 1 & 4.06 & .044 & 4.89 & .027 & 6.38 & .012 \\
\hline$t_{\mathrm{m}}=t_{\mathrm{f}}=0$ & 2 & 0.61 & .737 & 0.00 & 1.000 & 0.00 & 1.000 \\
\hline$h=z=0$ & 2 & 41.18 & $<.001$ & 47.66 & $<.001$ & 43.39 & $<.001$ \\
\hline$c=y=0$, and $i_{\mathrm{m}}=i_{\mathrm{f}}=i=1$ & 5 & 275.02 & $<.001$ & 249.16 & $<.001$ & 301.03 & $<.001$ \\
\hline No sex differences ${ }^{a}$ & 4 & 20.58 & $<.001$ & 16.90 & .002 & 15.78 & .003 \\
\hline Parsimonious model $^{b}$ & $3-4$ & 1.19 & .880 & 1.45 & .694 & 0.58 & .965 \\
\hline
\end{tabular}

aNo sex differences hypothesis: $i_{\mathrm{m}}=i_{\mathrm{f}}, b_{\mathrm{m}}=b_{\mathrm{f}}, b_{\mathrm{mm}}=b_{\mathrm{tf}}$, and $t_{\mathrm{m}}=t_{\mathrm{f}}$.

'Parsimonious model for SBP and MBP: $y=1, f_{\mathrm{m}}=f_{\mathrm{f}}$, and $t_{\mathrm{m}}=t_{\mathrm{f}}=0$, with $4 d f$, , and for DBP: $f_{\mathrm{m}}$ $=f_{\mathrm{f}}, t_{\mathrm{m}}=t_{\mathrm{f}}=0$, with $3 \mathrm{~d}$.f. 
TABLE VIII. Path Analysis of Phenotypes and Indices: Parameter Estimates ( \pm Standard Error) Under the General and Parsimonious Hypotheses for Systolic (SBP), Diastolic (DBP), and Mean Arterial (MBP) Blood Pressure

\begin{tabular}{|c|c|c|c|c|c|c|}
\hline & \multicolumn{2}{|c|}{ SBP } & \multicolumn{2}{|c|}{ DBP } & \multicolumn{2}{|c|}{ MBP } \\
\hline & General & Parsimony & General & Parsimony $^{b}$ & General & Parsimony ${ }^{\mathrm{a}}$ \\
\hline$h$ & $0.64 \pm 0.06$ & $0.67 \pm 0.04$ & $0.73 \pm 0.04$ & $0.72 \pm 0.04$ & $0.65 \pm 0.05$ & $0.63 \pm 0.04$ \\
\hline$z$ & $0.62 \pm 0.14$ & $0.58 \pm 0.11$ & $0.45 \pm 0.10$ & $0.46 \pm 0.10$ & $0.51 \pm 0.11$ & $0.52 \pm 0.12$ \\
\hline$c$ & $0.56 \pm 0.05$ & $0.56 \pm 0.04$ & $0.45 \pm 0.05$ & $0.46 \pm 0.06$ & $0.62 \pm 0.05$ & $0.63 \pm 0.03$ \\
\hline$y$ & $0.94 \pm 0.12$ & 1 & $1.41 \pm 0.18$ & $1.42 \pm 0.06$ & $1.05 \pm 0.10$ & 1 \\
\hline$u$ & $0.46 \pm 0.09$ & $0.48 \pm 0.08$ & $0.56 \pm 0.08$ & $0.56 \pm 0.19$ & $0.55 \pm 0.08$ & $0.55 \pm 0.08$ \\
\hline$i_{\mathrm{m}}$ & $0.95 \pm 0.11$ & $0.91 \pm 0.08$ & $0.82 \pm 0.06$ & $0.80 \pm 0.08$ & $0.82 \pm 0.06$ & $0.83 \pm 0.05$ \\
\hline$i_{\mathrm{f}}$ & $0.71 \pm 0.09$ & $0.69 \pm 0.08$ & $0.56 \pm 0.07$ & $0.56 \pm 0.06$ & $0.61 \pm 0.07$ & $0.61 \pm 0.07$ \\
\hline$i$ & $0.75 \pm 0.05$ & $0.75 \pm 0.05$ & $0.86 \pm 0.05$ & $0.85 \pm 0.06$ & $0.75 \pm 0.04$ & $0.74 \pm 0.04$ \\
\hline$f_{\mathrm{m}}$ & $0.12 \pm 0.07$ & $0.15 \pm 0.04$ & $0.14 \pm 0.09$ & $0.24 \pm 0.04$ & $0.20 \pm 0.09$ & $0.25 \pm 0.03$ \\
\hline$f_{\mathrm{f}}$ & $0.19 \pm 0.09$ & $0.15 \pm 0.04$ & $0.35 \pm 0.10$ & $0.24 \pm 0.04$ & $0.29 \pm 0.10$ & $0.25 \pm 0.03$ \\
\hline$b_{\mathrm{m}}$ & $0.37 \pm 0.11$ & $0.36 \pm 0.11$ & $0.77 \pm 0.06$ & $0.78 \pm 0.06$ & $0.51 \pm 0.09$ & $0.53 \pm 0.09$ \\
\hline$b_{\mathrm{f}}$ & $0.85 \pm 0.06$ & $0.85 \pm 0.06$ & $0.36 \pm 0.13$ & $0.39 \pm 0.13$ & $0.84 \pm 0.06$ & $0.85 \pm 0.05$ \\
\hline$b_{\mathrm{tm}}$ & $0.85 \pm 0.09$ & $0.83 \pm 0.09$ & $0.26 \pm 0.23$ & $0.25 \pm 0.24$ & $0.74 \pm 0.09$ & $0.72 \pm 0.09$ \\
\hline$b_{\mathrm{tf}}$ & $0.40 \pm 0.19$ & $0.47 \pm 0.14$ & $0.84 \pm 0.06$ & $0.83 \pm 0.07$ & $0.22 \pm 0.21$ & $0.19 \pm 0.21$ \\
\hline$t_{\mathrm{m}}$ & $0.17 \pm 0.39$ & 0 & $0.0^{\mathrm{c}}$ & 0 & $0.0^{\mathrm{c}}$ & 0 \\
\hline$\underline{t_{\mathrm{f}}}$ & $0.62 \pm 0.28$ & 0 & $0.0^{\mathrm{c}}$ & 0 & $0.01 \pm 0.45$ & 0 \\
\hline
\end{tabular}

aParsimonious model for SBP and MBP is $y=1, f_{\mathrm{m}}=f_{\mathrm{f}}$, and $t_{\mathrm{m}}=t_{\mathrm{f}}=0$.

barsimonious model for DBP is $f_{\mathrm{m}}=f_{\mathrm{f}}$, and $t_{\mathrm{m}}=t_{\mathrm{f}}=0$.

'Parameter went to boundary value during iteration.

$\left(c^{2} y^{2}=0.43\right)$ than in offspring $\left(c^{2}=0.21\right)$ for DBP. The effect of nontransmitted common sibship environment was higher in females than males, but the reverse was found for DBP with lower female than male values. An inverse pattern was seen for the common twinship environmental effect.

\section{DISCUSSION}

An extension of a nuclear family path model was presented in which twins and adopted offspring were included in addition to singleton offspring. The path model incorporated sex-specific effects of nontransmitted common sibship environments and introduced additional sources of twin resemblance. The model was applied to systolic, diastolic, and mean arterial blood pressure data from a French Canadian family study. In all, a random sample of 374 nuclear families was analyzed, which included $64 \mathrm{MZ}$ twin pairs, $66 \mathrm{DZ}$ twin pairs, and 145 adopted offspring. Environmental indices (estimates of familial environment) were generated for each individual using information from a pool of over 100 correlates of blood pressure. Given this highly informative study design, our primary goal was to obtain the most accurate resolution of genetic and environmental effects on blood pressure, paying special attention to the possible existence of gender-specific sibling effects and additional resemblance unique to twins. A second goal was to evaluate if the use of environmental indices distorted the inference. A third goal was to determine if twins and adoptees provided evidence consistent with the rest of the data. Toward these goals, the data were analyzed in three different ways.

First, the BP phenotypic data were analyzed without using BP indices. As the general model is not identified in this reduced data set, two assumptions had to be 
made. The heritabilities were assumed to be the same in parents and children, and the additional environmental similarity unique to twins was constrained so that the familial environments of twins were perfectly correlated. Second, both BP phenotype and index data were analyzed, which is the major thrust of this report. Third, phenotypes and indices were analyzed using only regular nuclear families (i.e., by excluding twin relationships and adoptees). This latter analysis was recently presented elsewhere [Pérusse et al., 1989]. Table IX summarizes estimates of genetic and cultural heritabilities in parents and children, as obtained from each of the three sets of analyses.

In order to determine if the use of twins and adoptees provide evidence consistent with the rest of the data, we compared columns 2 (all data used) and 3 (twins and adoptees excluded) in Table IX. This comparison shows that the two sets of estimates are remarkably similar, suggesting that the addition of twins and adoptees may not have influenced the results unduly. An exception is the estimate of cultural heritability in children $\left(c^{2}\right)$ for DBP, which is considerably smaller when twins and adoptees are included $(0.21 \pm 0.05)$ as compared to that when they were excluded $(0.42 \pm 0.05)$. However, cultural heritability in parents $\left(c^{2} y^{2}\right)$ using all relatives was identical with that when twins and adoptees were excluded $(0.42)$. The decrease in $c^{2}$ for children using all data was accompanied by a compensatory increase in the residual variance $\left(1-h^{2}-c^{2}\right)$, not in the estimate of genetic heritability. A possible explanation is that the adopted sibling correlation (from Table IV) is much smaller for DBP (0.186), which may have had a large effect on decreasing the offspring estimate of $c^{2}$. In comparison, the adopted sibling DBP correlation from an adoption study [Annest et al., 1979] was 0.286. Another apparent exception is the estimate of genetic heritability in children $\left(h^{2}\right)$ for MBP, which is smaller when twins and

TABLE IX. Estimates of Heritabilities ( \pm Standard Errors) Under the Most Parsimonious Models for Each of Three Data Sets

\begin{tabular}{|c|c|c|c|}
\hline Parameter & Phenotype only: all relatives ${ }^{\mathrm{a}}$ & Phenotype-index: all relatives & $\begin{array}{l}\text { Phenotype-index excluding } \\
\text { twins and adoptees }\end{array}$ \\
\hline \multicolumn{4}{|l|}{ SBP } \\
\hline$h^{2}$ & $0.16 \pm 0.10$ & $0.45 \pm 0.05$ & $0.49 \pm 0.10$ \\
\hline$h^{2} z^{2}$ & - & $0.15 \pm 0.05$ & $0.18 \pm 0.07$ \\
\hline$c^{2}$ & $0.53 \pm 0.09$ & $0.31 \pm 0.04$ & $0.31 \pm 0.06$ \\
\hline$c^{2} y^{2}$ & - & $0.31 \pm 0.04$ & $0.31 \pm 0.06$ \\
\hline \multicolumn{4}{|l|}{ DBP } \\
\hline$h^{2}$ & $0.33 \pm 0.10$ & $0.52 \pm 0.06$ & $0.52 \pm 0.09$ \\
\hline$h^{2} z^{2}$ & - & $0.11 \pm 0.04$ & $0.08 \pm 0.05$ \\
\hline$c^{2}$ & $0.37 \pm 0.10$ & $0.21 \pm 0.05$ & $0.42 \pm 0.05$ \\
\hline$c^{2} y^{2}$ & - & $0.42 \pm 0.05$ & $0.42 \pm 0.05$ \\
\hline \multicolumn{4}{|l|}{ MBP } \\
\hline$h^{2}$ & $0.28 \pm 0.10$ & $0.40 \pm 0.05$ & $0.56 \pm 0.09$ \\
\hline$h^{2} z^{2}$ & - & $0.11 \pm 0.05$ & $0.12 \pm 0.05$ \\
\hline$c^{2}$ & $0.46 \pm 0.10$ & $0.40 \pm 0.04$ & $0.42 \pm 0.05$ \\
\hline$c^{2} y^{2}$ & - & $0.40 \pm 0.04$ & $0.42 \pm 0.05$ \\
\hline
\end{tabular}

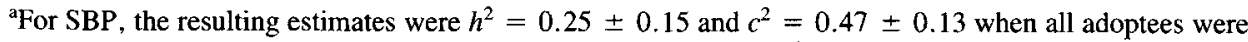
deleted, and those estimates are not significantly different from $h^{2}=0.45$ and $c^{2}=0.31$, as obtained from the combined data set (second column; $\chi_{2}^{2}=1.75, P=.417$ ).

${ }^{\mathrm{b}}$ These results were reported elsewhere [Pérusse et al., 1989]. 
adoptees were included $(0.40 \pm 0.05$ vs. $0.56 \pm 0.09)$. However, as judged by their standard errors, these estimates are not all that different. These results suggest that overall the genetic and environmental estimates are stable with or without the addition of twins and adoptees, with the exception of a possible influence of the adoptees in estimates of cultural heritability for DBP.

To evaluate the effect of using environmental indices, one may compare columns 1 (BP phenotype only) and 2 (BP phenotype and index) from Table IX. Although the results may at first seem very discrepant, they are quite compatible, at least for DBP and MBP. Recall that for analysis of phenotype data alone without indices (column 1), the heritabilities were assumed equal in parents and children. Accordingly, one should expect the resulting estimates to be between the corresponding estimates for parents and children as obtained from phenotypes and indices (column 2). For example, the estimated DBP $h^{2}$ from phenotypic data $(0.33 \pm 0.10)$ is close to the average of the estimates for parents $(0.11 \pm 0.04)$ and children $(0.52 \pm$ 0.06). All the estimates compare very well for DBP and MBP but are quite different for SBP. The estimate of $h^{2} z^{2}$ for SBP phenotype-index data $(0.15 \pm 0.05)$ is almost identical with that obtained from the phenotypic data alone $(0.16 \pm 0.10)$. However, this latter estimate is quite different from the offspring $h^{2}$ estimate from the phenotype-index data $(0.45 \pm 0.05)$. Also, $c^{2}$ is greater when indices were not used $(0.53 \pm 0.09)$ than when they were used $(0.31 \pm 0.04)$. There is at least one possible explanation for the observed differences in the phenotype-only vs. phenotypeindex models for SBP. The former model relies heavily on adoptive relationships for information about the environment. Thus, the higher cultural and lower genetic estimates may have been influenced by the very high adopted sibling SBP correlation (0.397) as compared to the adoptive sibling correlation reported by Annest et al. [1979], which was much lower (0.164). A possible explanation for the higher adoptive sibling correlation in the present study than in Annest et al. [1979] is that selective placement may have occurred for a correlated trait such as socioeconomic status. In fact, when adoptees are dropped from the current study, the phenotypic data yield $h^{2}(0.25 \pm 0.15)$ and $c^{2}(0.47 \pm 0.13)$ estimates consistent with the phenotype and index data.

These results suggest that the use of environmental indices in this study has not distorted the inference noticeably, although the adoptees may have influenced the results for SBP when no index information was used. It should be noted that neglecting possible genetic correlations between the phenotype and index is known to overestimate $c^{2}$ and underestimate $h^{2}$ by a like amount. However, the preceding discussion on the comparability of the two sets of estimates suggests that even if indices involve genetic effects they have not significantly impacted the results.

A comparison of the standard errors across the three sets of estimates reported in Table IX suggests that the combined data set using phenotypes, indices, twins, and adoptees (column 2) provides the most accurate and precise estimates of the parameters. For each of the BP phenotypes, significant genetic and common environmental effects were found, which tend to be generally higher than those reported by other investigators using family data (except for genetic heritability in parents) and lower than reports based on twin data. For example, several family studies [for reviews, see Williams et al., 1984; Burns and Lauer, 1986] reported SBP genetic heritabilities in the range of about $10 \%$ to $40 \%$, while in the present study parent 
and offspring heritabilities were $15 \%$ and $45 \%$, respectively. One previous study [Krieger et al., 1980] also found intergenerational differences in parents (41\%) and offspring (14\%) genetic SBP heritabilities. For DBP, the earlier reports of genetic heritabilities range from about $5 \%$ to $40 \%$, with those from the current study being $11 \%$ and $52 \%$ for parents and offspring, respectively. In addition, intergenerational differences in cultural heritability were found for DBP, with higher parent (0.42) than offspring (0.21) estimates. Another study, [Morton et al., 1980] also reported differential cultural heritabilities, with higher parent $(0.20)$ than offspring (0.09) estimates.

A possible explanation for the intergenerational differences in heritabilities is the presence of dominance deviations, which tend to increase sibling correlations relative to parent-offspring correlations. However, it appears unlikely to be the case here, since dominance deviations, if present, should increase the $\mathrm{MZ}$ correlation even more, resulting in higher estimates of genetic heritability from twin data alone. One can readily verify from Table IV that the two twin correlations alone yield genetic heritability estimates of no more than $23 \%$. Thus, there is little evidence to suggest dominance deviations. Interestingly, the twin data here yield considerably smaller estimates of genetic heritability than most other twin studies; i.e., $82 \%$ and $64 \%$ in adult twins for SBP and DBP, respectively [Feinleib and Garrison, 1979], and 23\% and $53 \%$ in 7 -year-old twins, respectively [Havlik et al., 1979]. Although the magnitude of the twin correlations here (about 0.7 and 0.6 for MZs and DZs, respectively) are higher than previous estimates (e.g., 0.55 and 0.25 , respectively) [Feinleib and Garrison, 1979], the twin difference here is smaller. A possible explanation for the higher twin correlations here is that all family members cohabitate, which tends to increase familial resemblance if common environment is important. Further, if the effect of cohabitation is to increase DZ correlations more than those for MZs, then the twin difference would be smaller, leading to lower genetic heritabilities.

Other explanations for the higher offspring than parent genetic heritabilities are possible. For example, if environments are relatively more homogeneous in children than in parents (e.g., smaller residual variance), then higher childhood heritabilities would be expected. Indeed, residual variances are smaller for offspring SBP and MBP. Other possible explanations include gene-environment interactions, genes turning "off" as a function of age, or differential expression of genes at different ages.

Two unique findings are suggested by this study. First, there appear to be gender-specific effects for blood pressure. The sibling correlations for SBP and MBP suggest that females are more similar than males, and cross-gender siblings are intermediate, with the opposite pattern for DBP. This result was also verified for SBP without the use of indices, and was of borderline significance for MBP. No evidence was found to support specific gender effects in parent-offspring resemblance. Second, strong support was found for extra twin resemblance for blood pressure through nontransmitted common environmental sources. This extra twin effect is gender-specific and tends to be in the opposite direction from the sibling gender differences. The net effect of the combined sibling $(b)$ and twin $\left(b_{t}\right)$ parameter estimates is to make like-sex twins resemble each other more than oppositesex twins. A cohort effect might produce the discrepant pattern of results between 
siblings and twins since the latter would be more likely to be involved in similar agesex-appropriate activities than singleton siblings. Together, these results suggest that interactions involving gender and/or twinship may play an important role in the familial aggregation of blood pressure.

In summary, our estimates of genetic and cultural heritabilities for blood pressure phenotypes are significant and are generally higher than previously reported (except for parental genetic heritability). In addition, these estimates are consistent with or without the use of extensive environmental indices, although the use of indices results in more precise estimates. Overall, the estimates are stable with or without the addition of extended nuclear family members, with the exception of a probable adopted sibling effect on DBP cultural heritability when the index was not used. Finally, the use of these extended familial relationships in the nuclear family path model enables testing for additional sources of familial aggregation, which is not possible using the traditional nuclear family approach. For example, we were able to determine that the aggregation of blood pressure in nuclear families is gender-specific in the offspring generation and that extra twin resemblance is also important. These findings may have useful implications in the treatment of cardiovascular diseases. Thus, this study would suggest that combining all these factors results in a more comprehensive and accurate assessment of the relative roles of heredity and environment on blood pressure than has been previously possible.

\section{ACKNOWLEDGMENTS}

This study was partly supported by NIH and NIMH grants GM28719, HL33973, and $\mathrm{MH} 31302$.

\section{REFERENCES}

Akaike H (1974): A new look at the statistical model identification. IEEE Trans Automat Control AC. 19:716-723.

Annest JD, Sing CF, Biron P, Mongeau JG (1979): Familial aggregation of blood pressure and weight in adoptive families. II. Estimation of the relative contributions of genetic and common environmental factors to blood pressure correlations between family members. Am J Epidemiol 110:492-503.

Burns TL, Lauer RM (1986): Blood pressure in children. In Pierpont MEM, Moller JH (eds): “The Genetics of Cardiovascular Disease." Boston: Martinus Nijhoff, pp 305-317.

Després JP, Tremblay A, Thériault G, Pérusse L, Leblanc C, Bouchard C (1988): Relationships between body fatness, adipose tissue distribution and blood pressure in men and women. $\mathrm{J}$ Clin Epidemiol 41:889-897.

Feinleib M, Garrison RJ (1979): The contribution of family studies to the partitioning of population variation of blood pressure. In Sing CF, Skolnick M (eds): "Genetic Analysis of Common Diseases: Applications to Predictive Factors in Coronary Disease." New York: Alan R. Liss, Inc., pp 653-673.

Havlik RJ, Garrison RJ, Katz SH, Ellison RC, Feinleib M, Myrianthopoulos NC (1979): Detection of genetic variance in blood pressure of seven-year-old twins. Am J Epidemiol 109:512-516.

Krieger H, Morton NE, Rao DC, Azevedo E (1980): Familial determinants of blood pressure in Northeastern Brazil. Hum Genet 53:415-418.

Li CC (1975): "Path analysis: A primer." Pacific Grove: Boxwood.

Morton NE, Gulbrandsen CL, Rao DC, Rhoads GG, Kagan A (1980): Determinants of blood pressure in Japanese-American families. Hum Genet 53:261-266.

Pérusse L, Rice T, Bouchard C, Vogler GP, Rao DC (1989): Cardiovascular risk factors in a French Cana- 
dian population: Resolution of genetic and familial environmental effects on blood pressure using extensive information on environmental correlates. Am J Hum Genet (in press).

Rao DC, Laskarzewski PM, Morrison JA, Khoury P, Kelly K, Wette R, Russell J, Glueck CJ (1982): The Cincinnati Lipid Research Clinic Family Study: Cultural and biological determinants of lipids and lipoprotein concentrations. Am J Hum Genet 34:888-903.

Rao DC, McGue M, Wette R, Glueck CJ (1984): Path analysis in genetic epidemiology. In Chakravarti A (ed): "Human Population Genetics: The Pittsburgh Symposium." Stroudsburg, PA: Van Nostrand Reinhold, pp 35-81.

Rao DC, Morton NE, Yee S (1974): Analysis of family resemblance. II. A linear model for familial correlation. Am J Hum Genet 26:331-359.

Williams RR, Dadone MM, Hunt SC, Jorde LB, Hopkins PN, Smith JB, Ash KO, Kuida H (1984): The genetic epidemiology of hypertension: A review of past studies and current results for 948 persons in 48 Utah pedigrees. In Rao DC, Elston RC, Kuller LH, Feinleib M, Carter C, Havlik R (eds): "Genetic Epidemiology of Coronary Heart Disease: Past, Present, and Future." New York: Alan R. Liss, Inc., pp 419-442.

Edited by Roger R. Williams 